\title{
An ontology for next generation e-Participation initiatives
}

\author{
Lukasz Porwol *, Adegboyega Ojo, John G. Breslin \\ Insight Centre for Data Analytics, National University of Ireland Galway, IDA Business Park, Galway, Ireland
}

\section{A R T I C L E I N F O}

\section{Article history:}

Received 28 November 2014

Received in revised form 13 May 2015

Accepted 18 January 2016

Available online xxxx

\section{Keywords:}

e-Participation

Duality of e-Participation

Participatory democracy

e-Participation initiative

e-Participation ontology

Online political deliberation

Social media

\begin{abstract}
A B S T R A C T
Despite over a decade-long experience of implementing e-Participation initiatives, there have been limited efforts so far to develop a detailed, comprehensive conceptualization for e-Participation considered from three distinct perspectives: as democratic process, a project and a deliberation platform. Current e-Participation literature is replete with fragmented models, which only partially describe aspects of e-Participation with main focus on structuring the "e-Participation" concept as a domain. This has made consistent descriptions and comparative analysis of e-Participation initiatives difficult, thus hindering the overall evolution of e-Participation. Consequently, no comprehensive, formal, executable e-Participation Ontology exists, that could be directly leveraged to facilitate operations of e-Participation initiatives or improving communication and knowledge exchange between similar e-Participation initiatives. In addition, current generation of e-Participation models does not explicitly support the emerging phenomenon of spontaneous, citizen-led e-Participation, in particular hosted on the social media platforms. This work bridges this gap by providing a practical, yet sufficiently detailed, conceptualization along with corresponding formal and executable ontology for next generation e-Participation. These semantic models cover the core facets of e-Participation - as a democratic process, an initiative and a sociotechnical system. The developed models also explicitly support the integrated citizen- and government-led model of e-Participation. For demonstration and validation, we employed the developed e-Participation Formal Ontology as a "design artefact" to describe two e-Participation initiatives at Local Government and European levels.
\end{abstract}

(c) 2016 Elsevier Inc. All rights reserved.

\section{Categories and subject descriptors}

D.4.7 [Organization and Design]: Interactive Systems

\section{General terms}

Design

Human factors

\section{Introduction}

e-Participation, in principle, employs technology-mediated dialogue between citizens and the politics sphere as well as between citizens and administration (Sabo, Rose, \& Skiftenesflak, 2008) to enable effective, concurrent public-participation and feedback (Chadwick, 2003) while also introducing new ways of political participation (Dijk, 2000).

e-Participation initiatives have been referred in the literature commonly as e-Consultation, web-based citizen input and online public engagement (Phang \& Kankanhalli, 2008).

\footnotetext{
* Corresponding author.

E-mail addresses: lukasz.porwol@insight-centre.org (L. Porwol), adegboyega.ojo@insight-centre.org (A. Ojo), john.breslin@insight-centre.org (J.G. Breslin).
}

The domain of e-Participation, in over a decade since its conception, has engendered different reference models as part of the foundations for multiform e-Participation projects and architectures. The predominant conceptualisations of e-Participation include: dimensions of eParticipation framework (Macintosh, 2004), levels of participation model (DESA, 2005), ladder of online participation (Li \& Bernoff, 2007), behaviour chain model (Fogg \& Eckles, 2007), e-Participation exploitation framework (Phang \& Kankanhalli, 2008), and a few other cited works (Aichholzer \& Westholm, 2009; Islam, 2008; Preece \& Shneiderman, 2009; Sæbø, Flak, \& Sein, 2011). However as we elaborated in our previous work (Reference removed for blind review) although these models address one or more aspects of e-Participation, the degree of complementarity of these models and the extent to which they collectively cover the scope of e-Participation are limited. The more elaborated models like e-Participation evaluation framework (Macintosh, 2008) and the domain model for e-Participation by Kalampokis, Tambouris, and Tarabanis (2008), drawing from e-Participation assessment framework (Tambouris, Liotas, \& Tarabanis, 2007a) are relatively comprehensive and present general conceptualization and categorization of e-Participation as a domain. Nevertheless, the works do not explicitly tackle the key e-Participation perspectives (initiative, project, platform) nor cover in sufficient detail such important aspects of e-Participation like deliberation, referring only briefly to discussion and political discourse as participation areas and identifying the stakeholders. Moreover existing models put more emphasis on assessment and evaluation 
of e-Participation rather than supporting e-Participation initiatives' operations. Most of the models are represented as textual frameworks with minimalistic, basic structure in a form of tables or simple diagrams and very few models are expressed in more formal or executable form. We argue that natural candidate for formal e-Participation models representation lies in ontologies understood as an explicit specification of a conceptualization, defined as a specification of a representational vocabulary for a domain (Gruber, 1993). In particular the conceptualization can be explained as classes and their relations in the domain of a discourse, which can be represented with a predicate calculus (Genesereth \& Nilsson, 1987). The purpose of an ontology is sharing and reuse of knowledge therefore this particular knowledgerepresentation type aligns perfectly with the identified mission of the e-Participation model. Recent efforts in the World Wide Web Consortium (W3C) to implement Semantic Web (Gruber, 1995), as a response to a need for shift from Web 2.0 to Web 3.0 have spurred interest in the use of ontologies for information modelling and knowledge representation. The main principle of Web 2.0 has been the collective intelligence, collaborative content creation and linking by the user (here citizen) who contributes towards common knowledge (O'reilly, 2007). However Web 2.0 did not specify how the information can be effectively processed and shared. Web 3.0 provides a common framework that allows data to be shared and reused across applications, enterprises, and community boundaries. Its well-defined data semantics enable computer agents and humans to work in cooperation (Tim Berners-Lee, James Hendler, \& Lassila, 2001). Ontologies provide a controlled vocabulary of terms that can collectively provide an abstract view of the domain (Schreiber \& Swick, 2006; Uschold \& Gruninger, 2009). Semantic Web technologies and ontologies are being used to address data discovery, data interoperability, knowledge sharing and collaboration problems. Ontologies can be described in RDF (Resource Description Framework) (Frank \& Eric, 2004) which provides a flexible graph based model, used to describe and relate resources.

Considering the formal ontologies for e-Participation, as a step towards more applied, executable e-Participation models, the domain has had very few contributions. This is a great disadvantage to the eParticipation platform developers, managers and administration, as eParticipation platforms, which currently largely rely on capabilities delivered by tools implementing standard Web 2.0 technologies, need specific standards and well-defined protocols for effective information management and interoperability. Many e-Participation projects such as HUWY, ${ }^{1}$ WAVE, ${ }^{2}$ VOICES, ${ }^{3}$ OCOPOMO, ${ }^{4}$ PADGETS, ${ }^{5}$ SPACES, ${ }^{6}$ NOMAD $^{7}$ or Puzzled by Policy ${ }^{8}$ employed Web 2.0 tools such as digital forums, blogs, wiki's and live-chat to provide dedicated e-Participation environment where citizens can express and discuss their needs and concerns. However, due to limitations of Web 2.0 the solutions fall short at addressing the problem of interoperability and miss standardized initiative descriptions backed by relevant ontologies. Moreover, the e-Participation platforms offered face significant problems with information overload, without capabilities to structure, cluster or summarize content, available for ontology-powered commercial solutions (Fensel et al., 2002; Spies, 2010; Sureephong, Chakpitak, Ouzrout, \& Bouras, 2008). The scarce ontological works for e-Participation include the ontology for an e-Participation virtual resource centre by Wimmer (2007) and much less popular e-Participation Ontology by Belák and Svátek (2010). The ontology by Wimmer (2007) considers eParticipation as a domain and focuses on structuring e-Participation research rather than facilitating the design and operation of e-

\footnotetext{
1 http://www.huwy.eu/vi.

2 http://www.wave-project.eu/.

${ }^{3}$ http://www.give-your-voice.eu/.

${ }^{4}$ http://www.ocopomo.eu/.

5 http://www.padgets.eu/.

${ }^{6}$ http://www.positivespaces.eu/.

http://www.nomad-project.eu/.

8 http://join.puzzledbypolicy.eu/.
}

Participation initiatives. In contrast, the ontology by Belák and Svátek (2010) is of a very applied nature; though it focuses mainly on deliberation and political debate and does not consider other pivotal aspects of e-Participation. Finally, a more recent work by Slaviero et al. (2011) builds upon models by Kalampokis et al. (2008), Tambouris, Liotas, and Tarabanis (2007b), Wimmer (2007) and delivers an ontology to support the deployment of e-Participation environments. However, the model, in principle, does not explicitly support the machineprocessable descriptions (for instance by leveraging existing standards and frameworks like $\mathrm{RDF}^{9}$ ) of e-Participation initiatives; the descriptions of models lack of detail on particular implementation or direct applicability of the ontologies to describing the e-Participation initiatives. Instead the ontologies intend to be used again for describing eParticipation as research domain or for describing e-Participation initiatives at more abstract level as tool supposedly to facilitate high level management and deployments of e-Participation environments. Consistent with the observation by Macintosh, Coleman, and Schneeberger (2009), we argue that e-Participation demands formal, inclusive methodology and more comprehensive models. These next generation eParticipation models are increasingly required to support constant automatic monitoring and engagement of citizens on Web 2.0 platforms as well as the explicit inclusion of spontaneous discussion on social media as integral part of the e-Participation process - duality of eParticipation. This has not been explicitly addressed by any of the models presented. Therefore, in our work on Integrated Model for eParticipation (Reference removed for blind review) we drawn from Giddens' Structuration Theory (Giddens, 1984) together with the complementary Dynamic Capabilities Theory (Teece, Pisano, Shuen, \& Shuen, 1997; Wang, 2007) to develop a conceptualisation of the duality of e-Participation and linked it to the classical models for e-Participation. Therefore, the presented model structures the citizen-to-decisionmaker communication and identifies the key e-Participation process capabilities required to implement both government-led and citizen-led e-Participation. From this model we have elicited a comprehensive matrix of e-Participation requirements and made a recommendation for the state-of-the art tools to satisfy e-Participation needs.

Building upon the Integrated Model as a solid theoretical base, this paper provides a comprehensive conceptualization and ontology for eParticipation. The model presented enables a detailed specification of e-Participation processes, facilitates collaboration and interoperability between various e-Participation initiatives as well as ensures better understanding of the needs of e-Participation stakeholders. Our major contribution is not limited to providing a comprehensive conceptualization and ontology for e-Participation, but also in providing a design artefact to support the integration of traditional government-led e-participation and spontaneous citizen-led e-Participation.

In next section of this document we elaborate more on the related work - the existing ontologies for e-Participation, highlighting the strong points of the works and the research gaps. In Section 3, we present our approach to constructing an ontology for e-Participation with relevant extensions to support the duality of e-Participation. In Section 4, we discuss the relevant e-Participation conceptualisation based on the Integrated Model for e-Participation. In Section 5, we present and elaborate on the model designed. In Section 6, we briefly validate the model. We discuss the results in Section 7 and present final conclusions in Section 8.

\section{Related work}

In this section, we examine in more detail the related works on existing e-Participation models to determine the research gaps to be tackled by our model. We focus on most prominent and elaborated models to ensure that selected models are largely representative of

\footnotetext{
${ }^{9}$ http://www.w3.org/RDF/.
} 
the state-of-the art of e-Participation. These models are discussed in turn below.

\subsection{Ontology for an e-Participation virtual resource centre (Wimmer, 2007)}

The main purpose of the model is to structure the e-Participation research for a virtual centre of excellence as an entry point on the domain knowledge for various stakeholders. The model identifies key eParticipation constructs along four dimensions of e-Participation: 1) participation areas (constructs: information provision, community building/collaborative environments, consultation, campaigning, electioneering, deliberation, discourse, mediation, spatial planning, polling, voting; 2) stakeholders involved (constructs: NGOs, government/executive, elected representatives, industry, political parties, politicians, citizen groups), 3) levels of engagement (constructs: eInforming, e-Consulting, e-Involving, e-Collaborating, e-Empowering) and 4) stages in policy making (constructs: agenda setting, policy formulation, decision making, policy implementation, policy evaluation) leaving e-Participation tools and technologies as additional, important branch linked to Participation areas, though beyond the eParticipation research and application dimensions space. The conceptualization is formally modelled as an executable ontology to be used by e-Participation community to ease finding and sharing e-Participation knowledge resources. The work was been carried as part of IST DEMO-net ${ }^{10}$ project an EC-funded Network of Excellence within the 6th Framework Program of the EC to investigate the e-Participation field of research and practise.

\subsection{A domain model for e-Participation (Kalampokis et al., 2008)}

The model was built to identify and describe the most significant aspects that characterize e-Participation domain. The design distinguishes three general e-Participation sub-domains along with basic constructs and sub-constructs: 1) participation process (constructs: scope, area (11 sub-construct areas), technique, activity, level (5 levels), outcome, policy cycle stage (5 stages), 2) ICT tool (constructs: channel (3 channels), technology (5 technologies), tool category (8 categories), 3 ) stakeholder (elected representative, government executive, political party, NGO/CSO, citizen group, academia research, industry)/role (constructs: owner/initiator, moderator/facilitator, decision makers, input provider). The conceptualisation has been modelled using UML (Universal Modelling Language) standard as a way to structure the eParticipation domain for easy domain exploration and to be leveraged to develop reference ontology for e-Participation information systems. The work was carried as part of IST DEMO-net project.

\subsection{Evaluation framework for e-Participation (Macintosh, 2008)}

The purpose of the model is to demonstrate a range of perspectives and methods to evaluate e-Participation initiatives. The framework distinguishes three perspectives on e-Participation evaluation along with relevant criteria: 1) democratic criteria (representation, engagement, transparency, conflict and consensus, political equality, community control), 2) project criteria (engaging with a wider audience, obtaining better informed opinions, enabling more in-depth consultation, cost effective analysis of contributions, providing feedback to citizens), 3) socio-technical criteria (Social acceptability - trust and security, relevance and legitimacy, Usefulness - accessibility, appeal ,content clarity, responsiveness, Usability - navigation and organization, efficiency and flexibility, error recovery). The framework also distinguishes targeted actors (citizens, councillors, engagement managers, project managers and technologists, moderators and administrators). The final

\footnotetext{
10 http://www.uni-koblenz-landau.de/campus-koblenz/fb4/iwvi/agvinf/projects/
} demo-net. set of constructs includes a range of six methods for e-Participation evaluation. The work steamed from the UK Local e-Democracy National Project.

All three models discussed present a significant level of granularity when describing e-Participation aspects, dimensions and constructs. The first two models (spawned from the same project - DEMO-net) have been designed to structure the e-Participation domain for knowledge exploration purposes. The purpose of the last model has been explicitly the evaluation of e-Participation initiatives nevertheless all the models share some basic constructs. The most common component appears to be the set of Stakeholders with relatively similar range of actors identified. The DEMO-net models focus on e-Participation areas, levels of engagement/participation and specific types of tools and technologies leveraged by particular e-Participation initiatives while the last model puts emphasis on three basic views of e-Participation (process, project, platform) and key aspects and requirements to be satisfied for each of the views. The domain view offered by the DEMO-net models brings sufficiently detailed, yet superficial view on e-Participation initiatives with very specific lists of categories, types and methods (appears quite 'static' and bound to example projects studied - less flexible) while the UK Local e-Democracy National Project spawned model delivers more fundamental constructs dealing with basic concepts of social-systems, user engagement and user-technology acceptance requirements. The wider perspective in the last model considering fundamental purpose of e-Participation makes the model more universal, hence providing constructs more applicable to future e-Participation developments.

In the following sections we describe our attempt to combine the aspects of e-Participation considered by the models discussed and to augment these aspects with concepts related to social-system principles and properties characteristic to citizen-discussions on Web 2.0 platforms and spontaneous citizen participation on social media. In particular, by delivering the model we tackle e-Participation aspects related to evaluation and e-Participation initiative maintenance (user-engagement and sustainability) as well as aspects important from the perspective of e-Participation knowledge storage, interoperability and knowledge exploration.

\section{Approach}

This section presents the approach we employed for the design of the e-Participation semantic model. The conceptual underpinning is presented in Section 3.1 followed by a description of the methodology in Section 3.2.

\subsection{Conceptual framework}

In this paper we build upon the conceptual framework created in our previous work which defines the e-Participation ontological space (Fig. 1) and the integrative framework for e-Participation. The

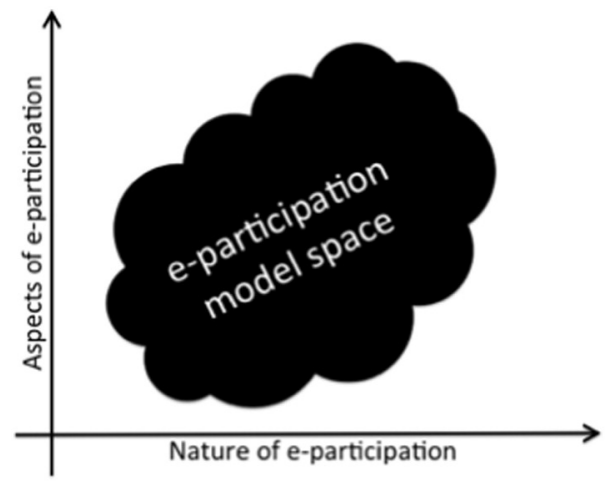

Fig. 1. e-Participation ontological space. 
framework distinguishes three different perspectives on the nature of e-Participation. Each of these perspectives is associated with four generic views. The resulting ontological space is described in Section 3.1.1 and the refined integration model in Section 3.1.2.

\subsubsection{E-Participation ontological space}

The integrative framework for e-Participation structures the eParticipation ontological space along three basic views of e-Participation (democratic perspective, project perspective and platform perspective) accordingly to the popular journalistic questions of what, when who, why, where and how (Yates \& Orlikowski, 2002) as a template for generating domain specific aspects. In particular the framework leverages Pepper's world hypotheses or views (Pepper, 1957) as a generic set of aspects for a phenomenon such as e-Participation. Our choice of the Pepper's world hypotheses is premised on the following: 1) the Pepper's views are metaphorically richer compared with the traditional journalistic questions and Aristotle four causes (Lombrozo, 2006); 2) the possibility of mapping Pepper's views to the journalistic questions and Aristotle four causes; and 3) evidence of the suitability of applying Pepper's hypotheses for structuring and analysing socio-technical systems (Marca \& McGowan, 1993). Pepper identified four different adequate views of the world: mechanism, formism, organicism and contextualism (Hayes, Hayes, \& Reese, 1988; Marca \& McGowan, 1993). In the context of eParticipation, Pepper's four views enable the specification of: eParticipation goals to be realized through some staged models (organicism); description of different entities involved in realizing a specified e-Participation goal (formism); the different functions, processes and systems required to produce desired e-Participation outputs or outcomes (mechanism); indication and evaluation of the experience of actors and observers of e-Participation system (contextualism).

\subsubsection{Integrated Model for e-Participation}

The Integrated Model for e-Participation (IMeP) presented in Fig. 2 is grounded in the integration of the Structuration Theory with the complementary, Dynamic Capabilities Theory in a single e-Participation social system model (Reference removed for blind review). IMeP employs two approaches to e-Participation: classic, government-led eParticipation and the new, citizen-led e-Participation. Following the Structuration Theory, these two modalities are exploited simultaneously to support the dynamic distribution of allocative and authoritative resources between citizens and decision makers in the context of decision or policy-making. Given appropriate resources, citizens exercise their agency to participate in the social-system re-production.

The legitimacy and significance of citizens' contribution to policy making is strengthened directly through dynamic capabilities (derived from Dynamic Capabilities Theory) developed by the governments leading to explicit acknowledgement, consideration and subsequent (partial) adoption. We have identified the following types of core capabilities for realizing such integrated e-Participation framework: 1) adaptive capabilities including dynamic resources (re-) distribution and acquisition, rules re-production and reformation process; 2) absorptive capabilities including continuous monitoring process, participation shaping process, citizen information services; and 3) innovative capabilities including flexible monitoring process and ubiquitous eParticipation. These capabilities ensure continuous reflexive dialogue and dialectics among citizens and between citizens and decision makers respectively characterizing the dual-nature e-Participation process.

e-Participation employs a deliberation process having a particular structure and properties within a particular context. The base requirement for a social system (here linked to the collaboration process) can be defined as a dialogue of at least two personal systems or people in their roles (Parsons, 1991). Therefore, in line with the definition the act of interaction between citizens and decision-makers together with their related concepts should be considered a social system. In order to leverage social system theoretical lens for e-Participation analysis it is necessary to enact first the fundamental and comprehensive eParticipation conceptualization.

\subsection{Methodology}

This section describes our approach to developing the eParticipation formal conceptualization or ontology. In our methodology we follow the design science research framework - DSRF (Table 1) (March \& Smith, 1995) as the core approach and we complement it by the three-staged Thalheim's construction workflow (Thalheim, 2011) serving as a best practise for technical model design and implementation processes. We adopt the DSRF to the specific needs of the context of e-Participation Ontology creation. In our context, the research outputs include: 1) the e-Participation constructs elicited, 2) the model generated, and the 3 ) instantiation by application of the executable

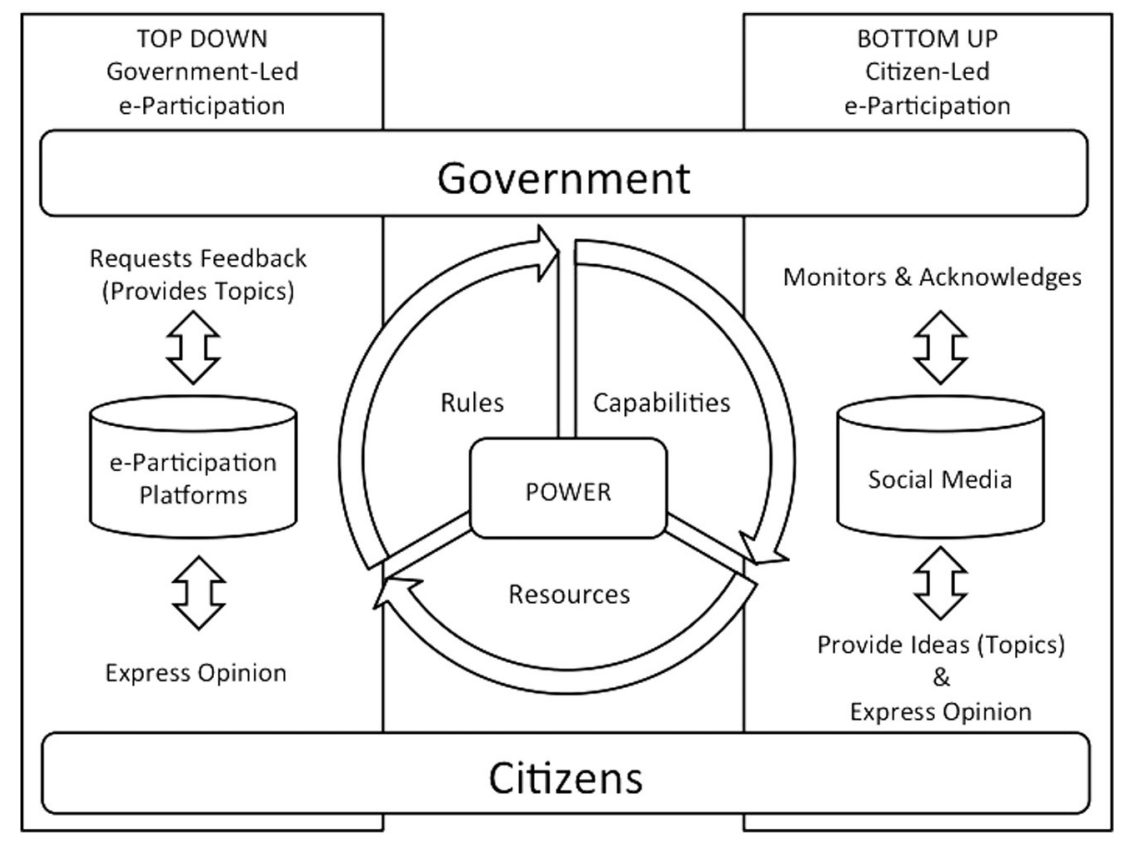

Fig. 2. Integrated Model for e-Participation. 
Table 1

Design science research framework

\begin{tabular}{|c|c|c|c|c|c|c|}
\hline & & \multicolumn{5}{|l|}{ Research activities } \\
\hline & & Build & Evaluate & Conclusions & Internal validity & External validity \\
\hline $\begin{array}{r}\text { Research } \\
\text { outputs }\end{array}$ & $\begin{array}{l}\text { Constructs } \\
\text { Model }\end{array}$ & $\begin{array}{l}\text { We elicit key e-Participation } \\
\text { concepts and relations from } \\
\text { competency questions } \\
\text { extrapolated from Integrated } \\
\text { Model for e-Participation. } \\
\text { We follow the key } \\
\text { model-properties and we aligned } \\
\text { them in competency questions } \\
\text { accordingly to the e-Participation } \\
\text { dimensions defined by the } \\
\text { integrative framework for } \\
\text { e-Participation. } \\
\text { Mapping the competency } \\
\text { questions to specific } \\
\text { e-Participation aspects entails } \\
\text { determining which of the three } \\
\text { perspectives of e-Participation } \\
\text { and which of the four generic } \\
\text { aspects of e-Participation are } \\
\text { addressed by the questions. The } \\
\text { unique subjects and objects were } \\
\text { selected as base-concepts. } \\
\text { Relations between concepts were } \\
\text { defined based on the common } \\
\text { knowledge. } \\
\text { After eliciting base-concepts and } \\
\text { defining the relations we use } \\
\text { available tool (NEOLOGISM) to } \\
\text { graphically represent the } \\
\text { concepts and relations in a form } \\
\text { of a graph. } \\
\text { We employed the model to } \\
\text { describe two existing } \\
\text { e-Participation initiatives. }\end{array}$ & $\begin{array}{l}\text { We claim the validity by } \\
\text { design, the concepts } \\
\text { leveraged for } \\
\text { constructing the model } \\
\text { are derived directly from } \\
\text { the competency } \\
\text { questions. }\end{array}$ & $\begin{array}{l}\text { Relevant conclusions } \\
\text { are drawn based on } \\
\text { the successful use of } \\
\text { the ontology in } \\
\text { describing } \\
\text { e-Participation } \\
\text { initiatives. }\end{array}$ & $\begin{array}{l}\text { Internal validity is } \\
\text { ensured by automatic } \\
\text { validation capability of } \\
\text { the data model } \\
\text { construction and data } \\
\text { population tool - } \\
\text { PROTÉGÉ }\end{array}$ & $\begin{array}{l}\text { Integrated Model for } \\
\text { e-Participation has been based } \\
\text { on rich state-of-the art review } \\
\text { and extends the up-to-date } \\
\text { e-Participation research models } \\
\text { with specific modes of } \\
\text { citizen-acknowledgment and } \\
\text { e-Participation reproduction } \\
\text { aspects. Therefore the model } \\
\text { represents rich source of } \\
\text { information on application } \\
\text { domain essential for the } \\
\text { relevance stage of the } \\
\text { construction workflow. The } \\
\text { reliability of the mapping has } \\
\text { been ensured through } \\
\text { "inter-observer" and "test-retest" } \\
\text { reliability tests (Bernard, 2000). }\end{array}$ \\
\hline
\end{tabular}

ontology in describing two example e-Participation initiatives. These output artefacts are obtained through the Thalheim's construction workflow-guided process encompassing the Relevance Stage for defining the concepts, Modelling Stage for formalizing the ontology and Realization Stage for leveraging the ontology in describing eParticipation initiatives. The research activities performed to design and implement the ontology include building (with a particular specification of what and how) and evaluating the model created. This is followed by relevant conclusions and validation of the model delivered.

We align explicitly our research activities and research outputs in Table 1.

The specific questions for our enquiry include:

R1. What are the key dimensions of e-Participation?

R2. What are the key competency questions for e-Participation conceptualization or final ontology?

R3. How can the competency questions be aligned with the four e-Participation dimensions described in Section 3.1.1 in the e-Participation integrative framework?

R4. Which key concepts can be elicited from the aligned eParticipation competency questions?

R5. How can the concepts be combined in a comprehensive eParticipation model?

R6. How can the model be leveraged for e-Participation case description?

Answering these questions is contingent on adoption of the Integrated Model for e-Participation as the application domain knowledge source then deriving the competency questions (representing the methods) and organizing them into twelve grid-themes delivered by integrating framework for e-Participation.

\section{E-participation conceptualization}

This section is intended to deliver a comprehensive e-Participation conceptualization with particular acknowledgement of duality of eParticipation.

We elicit a set of relevant e-Participation competency questions as view on e-Participation base-methods from the Integrated Model for e-Participation and then align the questions to the twelve distinct themes of the integrative framework for e-Participation. The questions are generated by following the information flow along with the stakeholders and tools (or instruments of execution) involved at each stage of e-Participation process in the Integrated Model while considering the concepts attached to particular aspect of e-Participation covered by the model in the context of dimension considered, drawn upon the integrative framework.

We present the aligned question-space in Table 2. For better clarity, every competency question has been given a unique identifier indicating the particular e-Participation view axis assignment. Here CQPL prefix refers to competency questions on sociotechnical platform view; CQPR refers to the project view and CQDP indicates questions related to the e-Participation democratic view. Accordingly to the generic view axis the questions referring to e-Participation entities are represented by the formism row. The mechanism row defines the questions on the e-Participation key functions and operations. Organicism refers to e-Participation goals and properties while contextualism considers matters of adoption, usability and evaluation.

We elicit the key e-Participation concepts from the questions defined. The concepts are defined based on subject, entity or action that the particular question refers to. The concepts are combined with contextual information to relate it to other elicited concepts accordingly to the type of the $5 \mathrm{~W} 1 \mathrm{H}$ question: what, when who, why, where and 
Table 2

e-Participation competency questions.

\begin{tabular}{|c|c|c|c|}
\hline \multirow[t]{2}{*}{ Generic view } & \multicolumn{3}{|l|}{ e-Participation Perspectives } \\
\hline & Sociotechnical system view & Project view & Democratic view \\
\hline Formism & $\begin{array}{l}\text { CQPL. } 1 \text { Who are the e-Participation actors? } \\
\text { CQPL. } 2 \text { What are the e-Participation tools? } \\
\text { CQPL. } 3 \text { What are the deliberation topics? } \\
\text { CQPL. } 4 \text { What level of user-engagement is } \\
\text { supported? } \\
\text { CQPL. } 5 \text { What type of communication is } \\
\text { supported? }\end{array}$ & $\begin{array}{l}\text { CQPR. } 1 \text { Who are the e-Participation project } \\
\text { stakeholders? } \\
\text { CQPR. } 2 \text { What are the e-Participation } \\
\text { channels leveraged? } \\
\text { CQPR.3 What is the e-Participation project } \\
\text { area? } \\
\text { CQPR. } 4 \text { What is the e-Participation project } \\
\text { funding? }\end{array}$ & $\begin{array}{l}\text { CQDP. } 1 \text { Who are the e-Participation democratic process } \\
\text { stakeholders? } \\
\text { CQDP.2 What are the e-Participation democratic process } \\
\text { instruments? } \\
\text { CQDP.3 What is the e-Participation problem domain? } \\
\text { CQDP.4 What level of stakeholder engagement is supported? }\end{array}$ \\
\hline Mechanism & $\begin{array}{l}\text { CQPL.6 How is the e-Participation platform } \\
\text { maintained? } \\
\text { CQPL.7 How discussions are monitored? } \\
\text { CQPL.8 How discussions are summarized? } \\
\text { CQPL.9 How is user-feedback supported? } \\
\text { CQPL.10 How user-engagement is supported? }\end{array}$ & $\begin{array}{l}\text { CQPR.5 How the e-Participation project is } \\
\text { disseminated? } \\
\text { CQPR. } 6 \text { How the e-Participation project } \\
\text { stakeholders are motivated? } \\
\text { CQPR.7 How the e-Participation project is } \\
\text { managed? }\end{array}$ & $\begin{array}{l}\text { CQDP.5 How is the e-Participation democratic process } \\
\text { started? } \\
\text { CQDP.6 How is the e-Participation democratic process } \\
\text { executed? } \\
\text { CQDP.7 How is the e-Participation democratic process } \\
\text { incorporated with policy-making process? }\end{array}$ \\
\hline Organicism & $\begin{array}{l}\text { CQPL.11 What is the aim of the deliberation? } \\
\text { CQPL.12 What is start time of the deliberation? } \\
\text { CQPL.13 What is end time of the deliberation? } \\
\text { CQPL.14 What is the result of deliberation? }\end{array}$ & $\begin{array}{l}\text { CQPR. } 8 \text { How much the e-Participation } \\
\text { project costs? } \\
\text { CQPR.9 When the e-Participation project } \\
\text { starts? } \\
\text { CQPR. } 10 \text { When the e-Participation project } \\
\text { ends? } \\
\text { CQPR. } 11 \text { What is the aim of the } \\
\text { e-Participation project? } \\
\text { CQPR. } 12 \text { What are the e-Participation } \\
\text { project results? }\end{array}$ & $\begin{array}{l}\text { CQDP. } 8 \text { Why the e-Participation democratic process is } \\
\text { performed? } \\
\text { CQDP.9 When the e-Participation democratic process starts? } \\
\text { CQDP.10 When the e-Participation democratic process } \\
\text { finishes? } \\
\text { CQDP. } 11 \text { What is the e-Participation democratic process } \\
\text { result? }\end{array}$ \\
\hline Contextualism & $\begin{array}{l}\text { CQPL.15 How the e-Participation platform } \\
\text { technical performance is evaluated? } \\
\text { CQPL.16 What is the technical performance of the } \\
\text { e-Participation platform? } \\
\text { CQPL.17 What is the level of Adoption of } \\
\text { e-Participation platform? } \\
\text { CQPL.18 What is the user-ranking of the } \\
\text { e-Participation platform? }\end{array}$ & $\begin{array}{l}\text { CQPR. } 13 \text { How the e-Participation project is } \\
\text { evaluated? } \\
\text { CQPR. } 14 \text { What is the performance of the } \\
\text { e-Participation project? }\end{array}$ & $\begin{array}{l}\text { CQDP. } 12 \text { How the e-Participation democratic process is } \\
\text { evaluated? } \\
\text { CQDP. } 13 \text { What is the performance of the e-Participation } \\
\text { democratic process? }\end{array}$ \\
\hline
\end{tabular}

how. The concepts are divided by the e-Participation view and grouped in three separate tables structured as followed: first position represents the unique identifier of the question, next the corresponding concept name followed by the relations between the elicited concepts.

Table 3

e-Participation platform conceptualization

\begin{tabular}{|c|c|c|}
\hline $\begin{array}{l}\text { Question } \\
\text { ID }\end{array}$ & Concepts & Relation \\
\hline CQPL.1 & Actor & $\begin{array}{l}\text { e-Participation has platform } \\
\text { Platform has actor } \\
\text { Actor is a subclass of person } \\
\text { Actor has subclass citizen } \\
\text { Actor has subclass decision maker } \\
\text { Actor has subclass facilitator }\end{array}$ \\
\hline CQPL.2 & Tool & Platform has tool \\
\hline CQPL.3 & Topic & $\begin{array}{l}\text { Platform has topic } \\
\text { Topic has discussion }\end{array}$ \\
\hline CQPL.4 & $\begin{array}{l}\text { User-engagement } \\
\text { level }\end{array}$ & Platform implements user engagement level \\
\hline CQPL.5 & Communication type & Platform implements communication type \\
\hline CQPL.6 & Platform maintenance & Platform has maintenance \\
\hline CQPL.7 & Discussion monitoring & Platform has discussion monitoring \\
\hline CQPL.8 & Discussion summary & Platform has discussion summary \\
\hline CQPL.9 & User-feedback & $\begin{array}{l}\text { Platform has user feedback } \\
\text { User feedback has user feedback direction }\end{array}$ \\
\hline CQPL.10 & User-engagement & Tool supports user engagement level \\
\hline CQPL.11 & Deliberation aim & Discussion has goal \\
\hline CQPL.12 & Deliberation start time & Discussion has start time \\
\hline CQPL.13 & Deliberation end time & Discussion has end time \\
\hline CQPL.14 & Deliberation result & Discussion has result \\
\hline CQPL.15 & $\begin{array}{l}\text { Technical performance } \\
\text { measure }\end{array}$ & Platform has technical performance measure \\
\hline CQPL.16 & Technical performance & $\begin{array}{l}\text { Technical performance measure has technical } \\
\text { performance value }\end{array}$ \\
\hline CQPL.17 & Adoption & Platform has adoption value \\
\hline CQPL.18 & Ranking & Platform has user ranking \\
\hline
\end{tabular}

Consequentially Table 3 lists the concepts derived from the questions with CQPL prefix, Table 4 from CQPR and finally Table 5 lists concepts elicited from CQDP type of questions. These conceptualizations are essential for the modelling stage of the Thalheim's workflow-based eParticipation model design. The concepts and relations (the base for methods) are presented in the way they can be directly mapped on the classes and properties of the end-model. The concepts presented are possibly generic to ensure clean and universal e-Participation model design.

Table 4

e-Participation project conceptualization.

\begin{tabular}{|c|c|c|}
\hline $\begin{array}{l}\text { Question } \\
\text { ID }\end{array}$ & Concepts & Relation \\
\hline CQPR.1 & Stakeholder & $\begin{array}{l}\text { e-Participation has project } \\
\text { Project has stakeholder } \\
\text { Stakeholder is a subclass of person } \\
\text { Stakeholder is a subclass of organization }\end{array}$ \\
\hline CQPR.2 & e-Participation channels & Project has e-Participation channel \\
\hline CQPR.3 & Domain & Project has domain \\
\hline CQPR.4 & Funding & Project has funding \\
\hline CQPR.5 & Dissemination & Project has dissemination \\
\hline CQPR.6 & $\begin{array}{l}\text { Stakeholder motivation } \\
\text { strategy }\end{array}$ & $\begin{array}{l}\text { Project has stakeholder motivation } \\
\text { strategy }\end{array}$ \\
\hline CQPR.7 & Management & Project has management \\
\hline CQPR.8 & Cost & Project has cost \\
\hline CQPR.9 & Start time & Project has start time \\
\hline CQPR.10 & End time & Project has end time \\
\hline CQPR.11 & Goal & Project has goal \\
\hline CQPR.12 & Result & Project has result \\
\hline CQPR.13 & Evaluation measure & Project has evaluation measure \\
\hline CQPR.14 & Performance & Project has performance value \\
\hline
\end{tabular}


Table 5

e-Participation democratic process conceptualization.

\begin{tabular}{|c|c|c|}
\hline $\begin{array}{l}\text { Question } \\
\text { ID }\end{array}$ & Concepts & Relation \\
\hline CQDP.1 & Stakeholder & $\begin{array}{l}\text { e-Participation has democratic process } \\
\text { Process has stakeholder } \\
\text { Stakeholder is a subclass of person } \\
\text { Stakeholder is a subclass of organization }\end{array}$ \\
\hline CQDP.2 & Instrument & Process has instrument \\
\hline CQDP.3 & Domain & Process has domain \\
\hline CQDP.4 & $\begin{array}{l}\text { User (citizen) engagement } \\
\text { level }\end{array}$ & Process enables user engagement level \\
\hline CQDP.5 & Trigger & Process has trigger \\
\hline CQDP.6 & Execution procedure & Process has execution procedure \\
\hline CQDP.7 & Policy making handle & Platform has policy making handle \\
\hline CQDP.8 & Goal & Process has goal \\
\hline CQDP.9 & Start time & Process has start time \\
\hline CQDP.10 & End time & Process has end time \\
\hline CQDP.11 & Result & Process has result \\
\hline CQDP.12 & Evaluation measure & Process has evaluation measure \\
\hline CQDP.13 & Performance & Process has performance value \\
\hline
\end{tabular}

\section{E-Participation model}

In this section we present the e-Participation model based on the concepts and relations defined in Section 4. First, we present a generic conceptual model for e-Participation (Fig. 3) showing the overall scope and dependencies of the intended end-model. The three major eParticipation views are represented with most descriptive concepts at this tentative presentation level we omit concepts that complement the particular e-Participation view. It is clear from the elicited concepts that the e-Participation platform is dependent on project and the project is linked closely to democratic process. The semantically overlapping concepts include stakeholder, result, domain and more importantly constraints like time, performance or goal. However the understanding of these concepts from particular view perspectives should be distinct. To highlight the strong implicit dependencies it is important to mention for example that the process domain influences the project focus area and that generates particular demand on the platform's main topic. On the other hand the platform's results and performance influence the project outcomes, which finally shape the democratic process overall performance. This however does not imply that in the model the concepts should create a hierarchy, as each one of them should be considered separately in the scope of the particular view.

The relations between the three different views of e-Participation are explained in detail further. Following the construction workflow in Fig. 4 we present the intended full e-Participation model.

\subsection{E-Participation model mission}

The main purpose of the model is to provide e-Participation creators, managers and champions with relevant tool for structured representation of key e-Participation aspects. This will help the e-Participation initiatives to be described in a more comprehensive way, therefore will contribute directly to better e-Participation knowledge representation, exchange and integration. Moreover the unified, standardized, machine-readable representation (RDF) will enable more coherent eParticipation initiatives' evaluation and comparison, facilitating the transparency through rich, open-data-enabled format. The model supports coherent e-Participation design with emphasis on the key aspects essential for the citizen-to-decision-maker dialoguesustainability and iterative e-Participation re-production. In particular the model explicitly addresses the duality of e-Participation through the acknowledgement of Web 2.0 discussions in e-Participation process, especially spontaneous citizen-contributions on social media, therefore significantly supports citizen-engagement as the key factor for e-Participation initiative success. Here it is important to emphasize that the model has been intentionally designed as a core model in order to ensure possibly universal applicability with details left to be specified on case-to-case bases - with refined, sub-domain-specific ontologies (such as deliberation ontology).

As discussed in the introduction and in the related work section, the state-of-the-art-literature does not provide an e-Participation Ontology that would cover comprehensively e-Participation as an initiative contingent on three main e-Participation aspects with explicit link to duality of e-Participation.

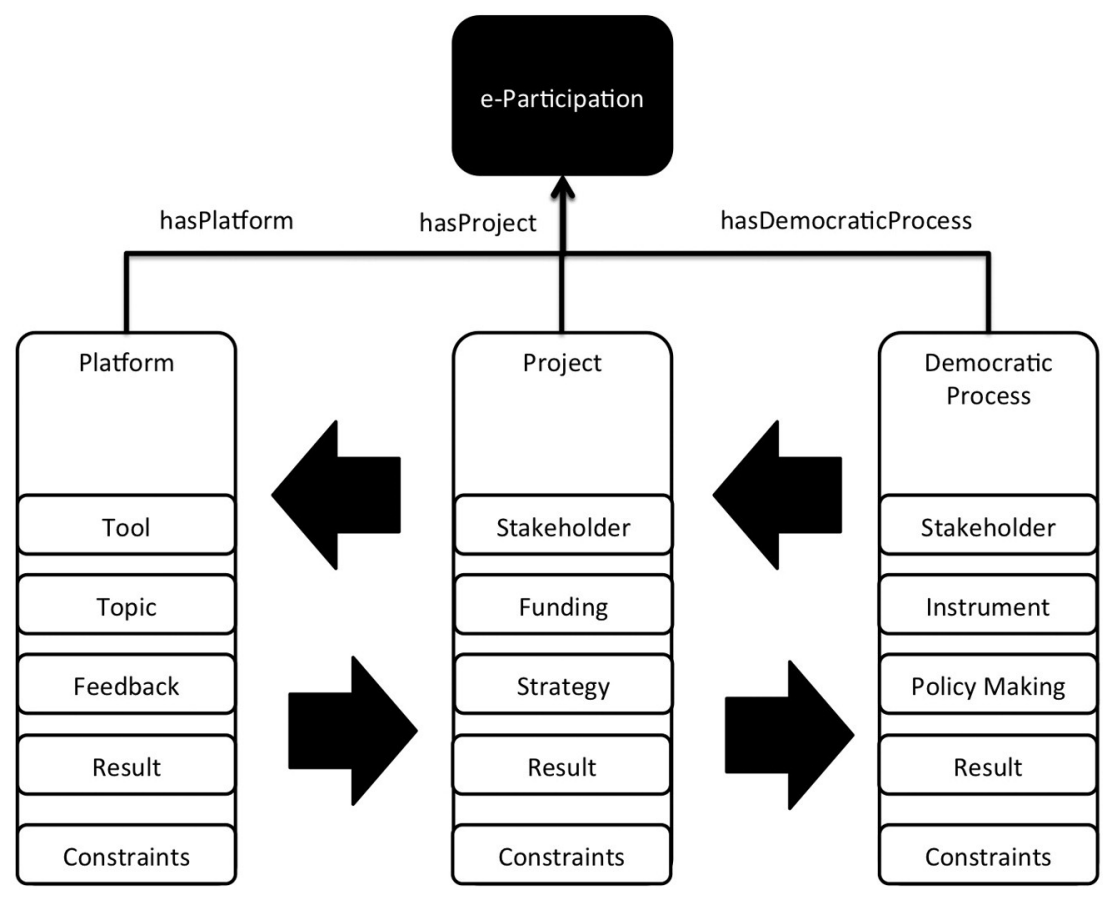

Fig. 3. e-Participation generic conceptual model. 


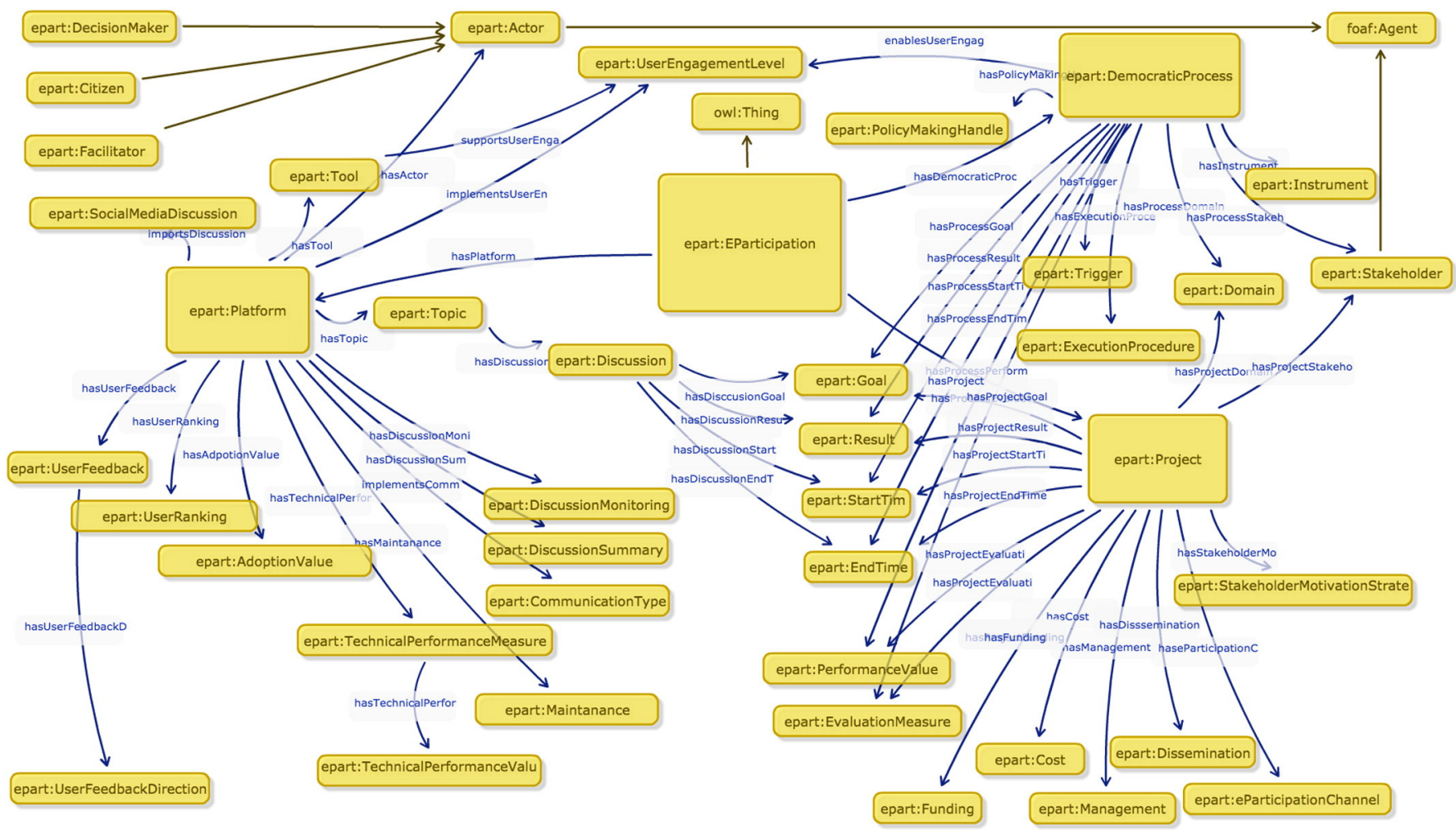

Fig. 4. e-Participation Ontology.

\subsection{E-participation model architecture and implementation}

In order to achieve maximum clarity of expression and sufficiently explicit model representation, enabling more comprehensive visualization, we incorporated the modelling stage and realization stage of the Thalheim's construction workflow (the conceptual model and the implementation of the model) in one single step. We represented the model using $\mathrm{RDF}^{11}$ - Resource Description Framework and OWL ${ }^{12}$ - Web ontology language. For the particular model implementation we leveraged the NEOLOGISM ${ }^{13}$ and PROTÉGÉ ${ }^{14}$ tools for the ontology design, description and visualization. NEOLOGISM is a vocabulary publishing platform for the Web of data, with a focus on ease of use and compatibility with Linked Data principles. Neologism is free and open source. As NEOLOGISM, supports RDF/OWL and enables direct ontology publishing, thus the full ontology representation can be provided if requested.

PROTÉGÉ is a well-established platform described as: a free, opensource ontology editor and framework for building intelligent systems. In this particular work we used the NEOLOGISM to build our ontology and then we leveraged PROTÉGÉ tool to validate the model and to populate it with relevant data.

The RDF technology used for the e-Participation model implementation, has been explicitly designed and developed to supply interoperability for information on the Web (Decker et al., 2000). The connected, structured data on the Web is called Linked Data (Bizer \& Berlin, 2009). The RDF information can be stored in a form of an interconnected knowledge graph in an RDF store (such as JENA TDB ${ }^{15}$ or SESAME ${ }^{16}$ ), which provides a standardized way of querying the graph - SPARQL endpoint utilizing the SPARQL ${ }^{17}$ query language. The RDF semantic interoperability

\footnotetext{
11 http://www.w3.org/RDF/.

12 http://www.w3.org/2001/sw/wiki/OWL.

13 http://neologism.deri.ie/.

14 http://protege.stanford.edu/.

15 http://jena.apache.org/documentation/tdb/.

16 http://www.openrdf.org/.

17 http://www.w3.org/TR/rdf-sparql-query/.
}

layer leverages ontologies as a means of describing the information. The RDF-represented concepts defined follow the best practise for ontology creation and explicitly express the key aspects of e-Participation domain. e-Participation model dependencies and deployment constraints.

In this section we discuss how the relations between the three distinct views of e-Participation: platform, project and process are reflected in the model design. We use the capitalized concept-names to link the considered content with the model presented on Fig. 4.

First, ideally the democratic process should initiate and drive the e-Participation initiative. It is the democratic process that should define the mission (policy making handle), key actors responsibility (Stakeholder - can be a person as well as an organization), execution (execution procedure), basic instruments of execution (such as relevant legislation, resources and tools), the scope (domain), the expected outcomes (result) and the initiation of e-Participation (trigger). The basic process definition and formal declaration are used to spawn a relevant e-Participation project within particular constraints of cost/funding and timeframe (start time, end time) executed by particular consortium of Stakeholders, with an expectation of comprehensive outcome (result). The project demands sufficient marketing and dissemination efforts within defined constraints in order to maximize the project impact. Here the expected impact has to be defined as an evaluation measure and aligned to the defined goal and will be finally expressed through performance value. The project uses the resources assigned to realize e-Participation, facilitated by the project management team. The common realization of the e-Participation channel is a particular e-Participation platform where the maintenance is entrusted to the project team who designs the platform or delegates the platform-development to external service providers. The platform is built with available tools enabling fast and easy citizens-to-citizens and citizens-to-decision-makers (dependable on user feedback direction) communication (user feedback) in a form of structured discussion on particular topic within the initiative domain. Here the communication type provided can be synchronous (for instance a live-chat) or asynchronous (forum, blog etc.). Additionally, 
the discussion on the platform is extended with deliberation on social media through relevant spontaneous citizen-discussion monitoring services that filters, analyse, shortlist and link related bottom-up citizengenerated content. The monitoring can leverage multiple tools to incorporate various social media channels into the platform and enable backlink to social media original content as well as to facilitate the communication with the content creators - social media users. The platform performance is evaluated accordingly to technical performance measures defined and expressed by particular technical performance value. Finally in order to deal with information overload and facilitate information exploration the discussion is summarized (discussion summary) either in an automatic or manual manner and published in a form of platform discussion result along with citizen-satisfaction expressed in user ranking. The result, together with user ranking and the technical performance value are important elements of the e-Participation project outcomes reporting and finally decide about the overall e-Participation democratic process performance as a part of e-Participation re-production effort.

\subsection{E-Participation model use-cases}

In this section we are discussing example use of the presented ontology for two different real-world e-Participation initiative cases. The first case study involves a transportation e-Participation forum established in 2011 as a volunteer initiative in Galway, Republic of Ireland, to identify a range of implementable, short-term traffic measures that could help alleviate some of the city-transport difficulties. The core idea behind the solution has been to address the participation barriers, especially in context of social inclusion and impact on policy-making. The project involved most major local transportation stakeholder groups, ranging from government officials to ordinary citizens. The diverse group of stakeholders includes: the mayor, chamber of commerce, local development authorities, representatives of the enterprise sector, academia (especially civil engineering, social science and computer science), along with independent volunteers and finally the citizens.

In this part of the document we show how we used our e-Participation Ontology to represent the information about the transportation eParticipation initiative as means of e-Participation model evaluation.

In order to generate the dataset discussed, we uploaded our ontology into PROTÉGÉ tool and leveraged the provided interface to populate the ontology with relevant data accordingly to the schema defined. Considering limited space of this document we restrict ourselves to show just few representative examples of the ontology-based description creation. Nevertheless, it is possible to request a full RDF description of the initiatives presented.

Fig. 5 presents PROTÉGÉ interface with the ontology tree expanded on the left hand side along with the particular individual - here the platform actor expanded. The particular actor is of type decision maker and it is the mayor of the city where the transportation deliberation is taking place. On the right hand side we can see the name of the mayor specified. This simple example enables us to conclude that the platform has active user, here decision-maker, the mayor of the city, whose participation is of great value considering the citizenengagement on the platform. Fig. 6 presents a view on dissemination individuals set, which includes online, press and radio dissemination. As it can be learnt from the figure the press dissemination efforts for the transportation e-Participation initiative involved local newspapers such as Galway Advertiser and Galway Independent. This is an important fact considering that these two positions are the most popular press in Galway City area and are an important communication channels reaching most of the local population.

The examples presented highlight the base structure of the use of the e-Participation Ontology for the transportation initiative in Galway. What can be observed immediately is that the data recorded has very rigid, typed format therefore can be machine processed directly and this facilitates easy data exploration and management. For instance the individual's data on Press dissemination in Fig. 6 is represented as top data property of string type. This indicates explicitly (to the human or machine exploring the data) the way the particular content can be extracted and processed. Similarly to the example presented we have described the whole transportation e-Participation initiative accordingly to the defined ontology. The result has a form of a publishable RDF file that can be uploaded to any website or can be stored as query-able knowledge-base and exposed on the web via SPARQL endpoint for full information transparency in-line with the Open-Data principle. The e-Participation initiative description, represented and stored in this particular, highly-standardized form, can be easily published, shared and compared against similar initiatives therefore contributes towards more effective analysis hence facilitating eliciting success factors and generating detailed recommendations and best practise guidelines.

In order to verify the universality of the model we used our ontology to describe another e-Participation imitative (this time at European level) funded under FP7 EU framework - Puzzled by Policy. The project aims to reconnect citizens with politics and policymaking in the context of immigration in Europe. The multinational project gathering partners from Ireland, Greece, Slovenia, Italy, UK, Portugal, Netherlands, Spain

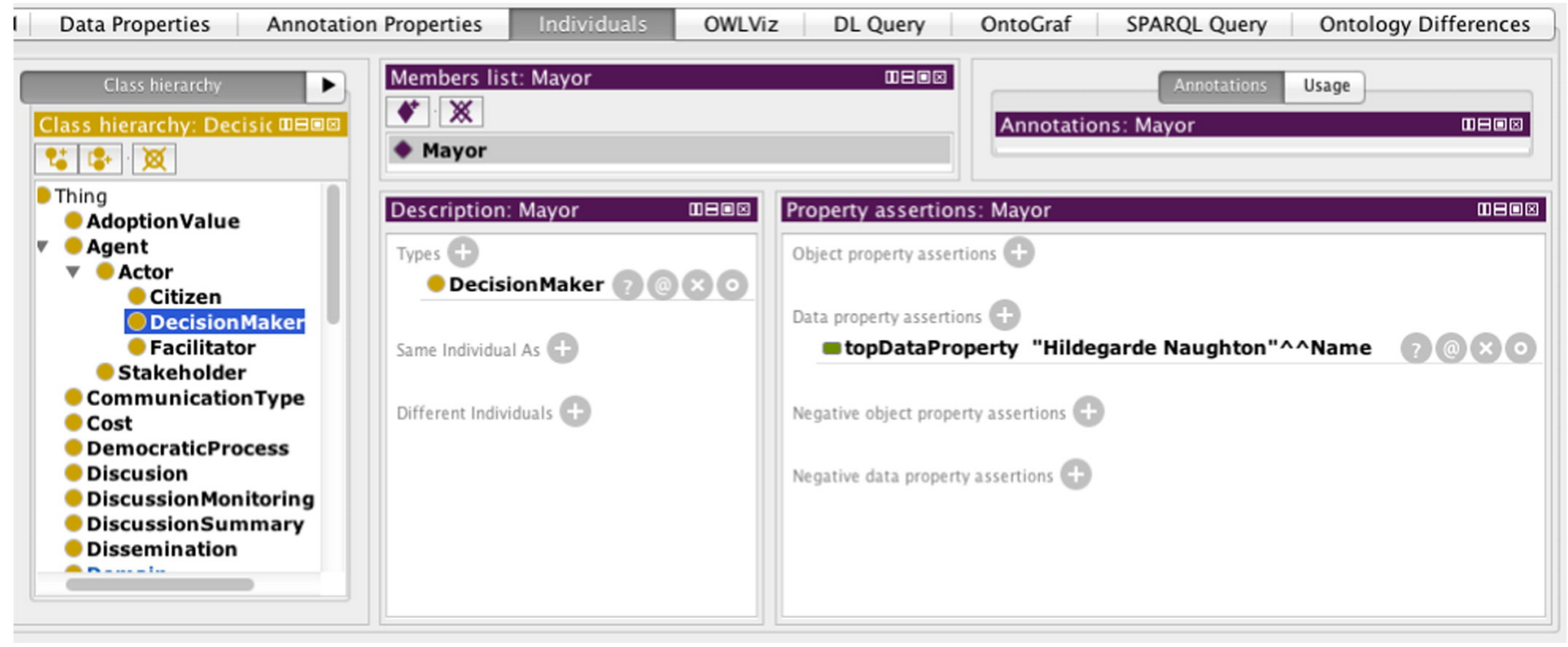

Fig. 5. Platform actor example. 


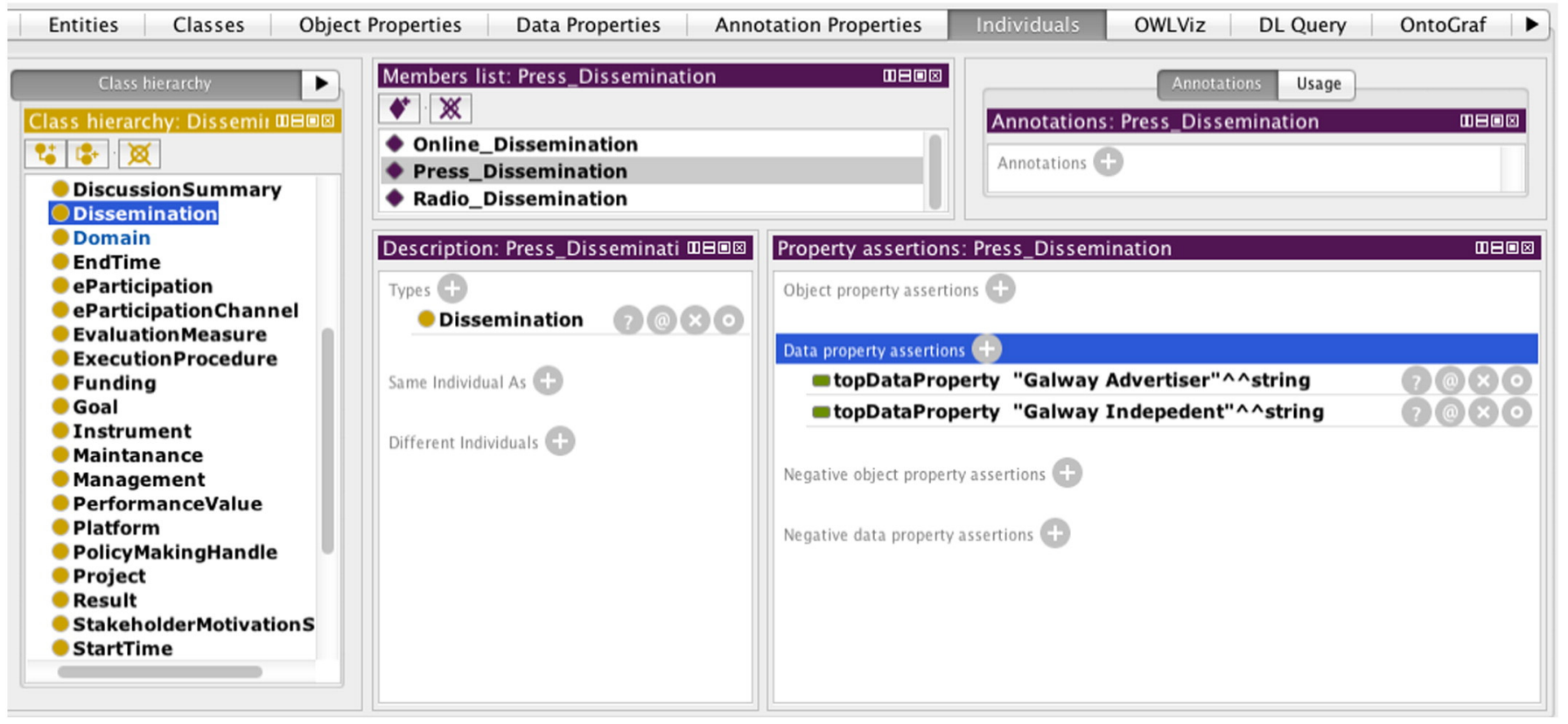

Fig. 6. Project dissemination example.

and Hungary contributes to the increase of public awareness on many aspects of immigration and to deliver relevant, objective information in presence of many confusing and politically biased opinions. The platform provided by the project in a form of a digital discussion forum has been expanded with a dedicated profiler tool to help citizens to identify their political standing.

We elaborate very briefly how we described the Puzzled by Policy content. In Fig. 7 we show how the goals of the initiative are specified, in particular the goal to improve EU immigration policies has been highlighted with details recorded as data property (Again, on request we can provide an RDF file with a complete, example initiative description).

From the application of the ontology to the context of this initiative we have learnt that particular pilots differ significantly in engagement of local authorities. For instance the Spanish and Greek pilots deployment showed far more politicians engaged than the Portuguese and Hungarian sites. Moreover the dissemination in the Spanish pilot in particular has been supported by mainstream media promotion through local newspapers that most probably decided about the overall better engagement on this pilot platform, in comparison to sister-deployments in other European countries.

Therefore even within this particular project, by applying our ontology for describing the local pilot initiatives, we were able to ensure more transparency and make basic comparisons that my lead to significant improvements and better stakeholder engagement for the eParticipation initiatives in the future.

\section{Validation}

In this section we validate the implementation of the e-Participation ontology. Our first argument for the validity of our ontological model with respect to the competency questions follows from the rigorous

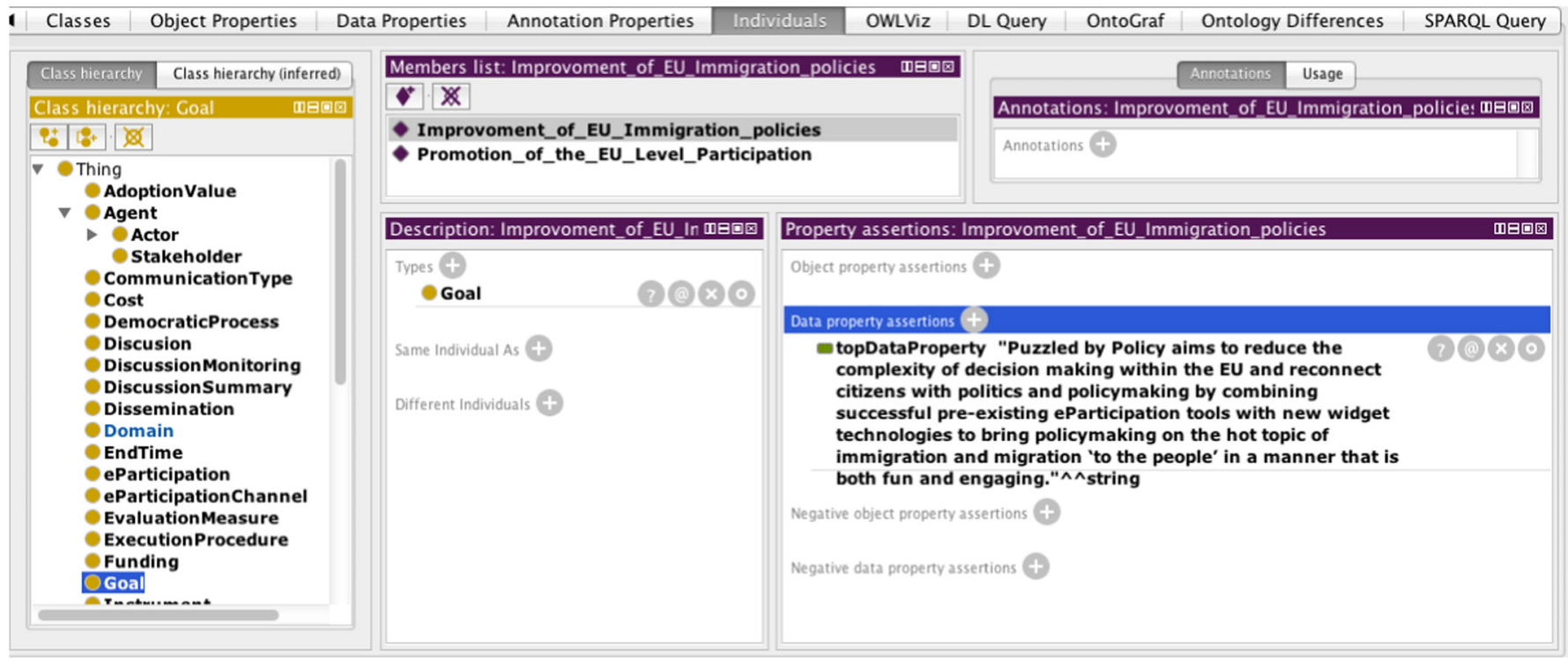

Fig. 7. Project goal example. 
design science research framework-based approach and from the fact that the ontology was generated explicitly from competency questions through Thalheim's construction workflow-based process. Therefore the question of whether the ontology answers the competency questions is trivially satisfied, i.e., the ontology is "correct by design". Secondly, regarding the internal consistency of the e-Participation Ontology (expressed in $\mathrm{RDF} / \mathrm{OWL}$ ), we verified that the ontology is coherent or without contradiction by using the PROTÉGÉ Pellet Reasoner tool. Thirdly, the utility practical relevance and universal character of the ontology was established through its use in encoding the two case studies of transportation and EU immigration e-Participation initiatives of very different nature and scale. Finally, the reliability of all the mappings has been ensured through "inter-observer" and "test-retest" reliability tests (Bernard, 2000).

\section{Discussion}

The e-Participation Ontology presented in this paper addresses the need for a comprehensive ontology for next generation eParticipation. The ontology extends the state of the art models with direct support for duality of e-Participation by: 1) enabling better eParticipation initiative transparency through more structured and machine-processable descriptions; 2) explicit incorporation of deliberation monitoring and summarisation elements; followed by 3 ) the integration of classic e-Participation channels with social media. Thus, by inclusion of deliberation information management tools and integration of spontaneous citizen-discussions with explicit citizen-acknowledgement and fast feedback we claim better sustainability and potentially increased citizen engagement for next generation e-Participation initiatives applying the model.

The result-ontology covers three distinct views of e-Participation: platform, project and democratic process. In principle the model enables better and more rigid e-Participation initiatives descriptions therefore supports more coherent comparisons and evaluations as well as facilitates the access, re-use and interoperability of the information about the initiatives, also as a contribution towards better next generation e-Participation solutions.

The semantic model construction process is rigorous and grounded in solid theoretical framework ensuring validity of the presented model. The e-Participation ontology design has been validated both internally and externally and we have shown the utility of the solution on two real-world e-Participation initiatives examples. Like any domain theory, we cannot claim the absolute completeness of the presented semantic model although our ontology has been designed gradually around the Integrated Model for e-Participation with particular acknowledgement of the issue of duality of e-Participation starting from the scientifically supported model going towards dedicated implementation; therefore we claim better alignment of our model to dual eParticipation needs.

As indicated in the introduction and related work section, this document acknowledges other significant contributions in structuring and conceptualizing e-Participation in particular works by Kalampokis et al. (2008), Tambouris et al. (2007b), and Wimmer (2007) and expands the set of constructs presented in that research with key aspects related to bottom-up e-Participation reflected by duality of e-Participation as well as structures the existing concepts in more coherent form, hence contributing to structuration of e-Participation domain. The ontology has been designed to be universal therefore in the form presented, only high level concepts are used, to be refined by specialized ontologies tuned to particular context in which the ontology will be deployed. These ontologies in particular should structure citizen-deliberations and citizen-todecision-maker communication, as well as resources flow within the initiative. Therefore the ontology presented should be considered a high level ontology for describing an e-Participation initiative as a whole, while leaving space to specific conceptualisations to be produced to support particular e-Participation processes.

\section{Conclusions}

Motivated by the need to provide the necessary step towards conceptualizing three major aspects of e-Participation, in a single model, enriched with a new perspective on the use of bottom-up eParticipation supported by integration of social media channels, we have presented a universal, core e-Participation Ontology for next generation e-Participation initiatives. We have demonstrated theoretically the usefulness of the model. Results from our work show immediate opportunities for consolidating and sharing knowledge about eParticipation initiatives important for building new, more effective solutions. Therefore this work contributes towards expanding and structuring e-Participation domain-knowledge. We acknowledge the limitations of the ontology as a generic model for describing eParticipation initiatives. The work presented demands further followup developments in a form of specialized ontologies for specific processes and aspects of e-Participation. However we argue that the ontology presented in this document contributes significantly towards better understanding of e-Participation as a very complex combination of context-dependent elements, while ensuring a solid base for the dedicated ontologies development.

As next steps, we intend to establish an e-Participation knowledgebase gathering information about e-Participation initiatives structured with our ontology. Furthers steps include design of first fine-grained ontology extending the core ontology with explicit support for deliberative political discourse management with particular acknowledgment of the duality of e-Participation. Finally we intend to design and implement a dedicated solution for next generation e-Participation and deploy the solution developed for selected e-Participation initiatives.

\section{References}

Aichholzer, G., \& Westholm, H. (2009). Evaluating eParticipation projects: Practical examples and outline of an evaluation framework. European Journal of ePractice, 1-18 March.

Belák, V., \& Svátek, V. (2010). Supporting self-organization in politics by the semantic web technologies, 1-8.

Bernard, H.R. (2000). Social research methods - Qualitative and quantitative approaches. SAGE Publications, Inc

Bizer, C., \& Berlin, F. U. (2009). Linked data - The story so far.

Chadwick, A. (2003). Bringing E-Democracy back in: Why it matters for future research on E-Governance. Social Science Computer Review, 21(4), 443-455. http://dx.doi.org/ 10.1177/0894439303256372.

Decker, S., Harmelen, F. Van, \& Broekstra, J. (2000). The semantic web - On the respective roles of XML and RDF, 1-19.

DESA (2005). UN global E-government readiness report 2005 from E-government to Einclusion.

Dijk, J.A.G.M. Van (2000). Models of democracy and concepts of communication.

Fensel, D., Van Harmelen, F., Ding, Y., Klein, M., Akkermans, H., Broekstra, J., ... Horrocks, I. (2002). Ontology-based knowledge management. Computer, 35(11), 56-59. http:// dx.doi.org/10.1109/MC.2002.1046975.

Fogg, B.J., \& Eckles, D. (2007). The behavior chain for online participation: How successful web services STRUCTURE PERSUASION, 199-209.

Frank, M., \& Eric, M. (2004). RDF Primer.

Genesereth, Michael R., \& Nilsson, N.J. (1987). Logical Foundations of Artificial Intelligence.

Giddens, A. (1984). The constitution of society: outline of the theory of structuration.

Gruber, T.R (1993). A translation approach to portable ontology specifications, (April).

Gruber, T.R. (1995). Toward principles for the design of ontologies used for knowledge sharing? International Journal of Human-Computer Studies, 43(5-6), 907-928. http:// dx.doi.org/10.1006/ijhc.1995.1081.

Hayes, S.C., Hayes, L.J., \& Reese, H.W. (1988). Finding the philosophical core: A review of Stephen C. Pepper's world hypotheses: A study in evidence. Journal of the Experimental Analysis of Behavior, 1(1), 97-111.

Islam, M.S. (2008). Towards a sustainable e-Participation implementation model. October October, 1-12.

Kalampokis, E., Tambouris, E., \& Tarabanis, K. (2008). A domain model for eParticipation. 2008 Third International Conference on Internet and Web Applications and Services (pp. 25-30). http://dx.doi.org/10.1109/ICIW.2008.69.

Li, C., \& Bernoff, J. (2007). Social technographics $®$ TRENDS. Forrester.

Lombrozo, T. (2006). The structure and function of explanations. Trends in Cognitive Sciences, 10(10), 464-470. http://dx.doi.org/10.1016/j.tics.2006.08.004.

Macintosh, A. (2004). Characterizing e-participation in policy-making. 37th Annual Hawaii International Conference on System Sciences, 2004. Proceedings of the, 00(C). http://dx.doi.org/10.1109/HICSS.2004.1265300 (10 pp.). 
Macintosh, A. (2008). Towards an evaluation framework for eParticipation. Transforming government: People, process and policy, 2.

Macintosh, A., Coleman, S., \& Schneeberger, A. (2009). eParticipation: The research gaps, $1-11$.

Marca, D., \& McGowan, C. (1993). Specification Approaches Express Different World hypotheses. Proceedings of the seventh international workshop on software specification and design, 1993 (pp. 214-223). IEEE.

March, S.T., \& Smith, G.F. (1995). Design and natural science research on information technology. Decision Support Systems, 15(4), 251-266. http://dx.doi.org/10.1016/ 0167-9236(94)00041-2.

O'reilly, T. (2007). What is Web 2.0: Design patterns and business models for the next generation of software. Communications and Strategies, 65(4578), 17-37. http://dx. doi.org/10.1109/KIMAS.2003.1245106.

Parsons, T. (1991). The social system. Psychology Press.

Pepper, S.C. (1957). World hypotheses, a study in evidence. Univ of California Press.

Phang, C.W., \& Kankanhalli, A. (2008). A framework of ICT exploitation for e-participation initiatives. Communications of the ACM, 51(12), 128. http://dx.doi.org/10.1145/ 1409360.1409385

Preece, J., \& Shneiderman, B. (2009). The reader-to-leader framework: Motivating technology-mediated social participation. Transactions on Human-Computer Interaction, 1(1), 13-32.

Sabo, O., Rose, J., \& Skiftenesflak, L. (2008). The shape of eParticipation: Characterizing an emerging research area. Government Information Quarterly, 25(3), 400-428. http://dx. doi.org/10.1016/j.giq.2007.04.007.

Sæbø, Ø., Flak, L.S., \& Sein, M.K. (2011). Understanding the dynamics in e-Participation initiatives: Looking through the genre and stakeholder lenses. Government Information Quarterly, 28(3), 416-425. http://dx.doi.org/10.1016/j.giq.2010.10.005.

Schreiber, R., \& Swick, G. (2006). Semantic web best practices and deployment working group.

Slaviero, C., Cristina, A., Garcia, B., Maciel, C., Federal, U., \& Rua, F. (2011). Towards an ontology to support the deployment of eParticipation environments, 146-160.

Spies, M. (2010). An ontology modelling perspective on business reporting. Information Systems, 35(4), 404-416. http://dx.doi.org/10.1016/j.is.2008.12.003.

Sureephong, P., Chakpitak, N., Ouzrout, Y., \& Bouras, A. (2008). An ontology-based knowledge management system for industry clusters. 1-10 (Retrieved from http://arxiv.org/abs/ 0806.0526).

Tambouris, E., Liotas, N., \& Tarabanis, K. (2007a). A framework for assessing eParticipation projects and tools. 40th Hawaii International Conference on System Sciences - 2007a (pp. 1-10).

Tambouris, E., Liotas, N., \& Tarabanis, K. (2007b). A framework for assessing eParticipation projects and tools, $1-10$.

Teece, D.J., Pisano, G., Shuen, A., \& Shuen, A.M.Y. (1997). Dynamic capabilities and strategic. Management, 18(7), 509-533.

Thalheim, B. (2011). The science of conceptual modelling, 12-26.

Tim Berners-Lee, James Hendler, \& Lassila, O. (2001). The semantic web. Scientific American.

Uschold, M., \& Gruninger, M. (2009). Ontologies: Principles, methods and applications. The Knowledge Engineering Review, 11(02), 93. http://dx.doi.org/10.1017/ S0269888900007797.

Wang, C.L. (2007). Dynamic capabilities: A review and research agenda dynamic capabilities. A Review and Research Agenda, 9(2007), 31-51.

Wimmer, M. a. (2007). Ontology for an e-participation virtual resource centre. Proceedings of the 1st International Conference on Theory and Practice of Electronic Governance -ICEGOV '07 (pp. 89). http://dx.doi.org/10.1145/1328057.1328079.

Yates, J., \& Orlikowski, W. (2002). Genre systems: Structuring interaction through communicative norms. Journal of Business Communication, 39(1), 13-35. http://dx.doi. org/10.1177/002194360203900102.
Lukasz Porwol is a PhD Student and a Researcher at the Insight Center for Data Analytics (formerly known as Digital Enterprise Research Institute - DERI), National University of Ireland, Galway; a leading center in Semantic Web and Linked Open Data research. At Insight@ Galway, his research work focuses on leveraging social media, games and mobile technologies to support effective dialogue between citizens and decision-makers Lukasz is an experienced leader, consultant and developer involved in multiple initiatives. He has been an active member of the Galway Transport Advisory Board as the IT lead and is the IT Director for the Computer \& Communications Museum of Ireland Limited. His background combines solid engineering and scientific knowledge (MSc in Computer Science and Eng. in Information Technologies).

Adegboyega Ojo is Senior Research Fellow and E-Government Unit Leader at the Insight Center for Data Analytics (formerly known as Digital Enterprise Research Institute DERI), National University of Ireland, Galway; a leading center in Semantic Web and Linked Open Data research.

At Insight @ Galway, his research and development work addresses how public organizations can effectively leverage Linked Open Government Data for public service and policy innovation. Before his current role, he worked as Academic Program Officer and Research Fellow at the Center for Electronic Governance, United Nations University - International Institute for Software Technology (UNU).

At UNU, he supported governments in Africa, Asia, and Latin America; including Macao, Korea, Mongolia, Colombia, Cameroon and Nigeria. His expertise in E-Government is in the areas of Strategies, Architecture and Standards, Measurement, Software Infrastructure Whole-of-Government models and Linked Open Government Data.

Before his international engagements, he was Senior Lecturer in Computer Science at the University of Lagos, Nigeria, where he earlier earned his doctorate and bachelor degrees in 1998 And 1991 respectively. He is a member of Computer Professionals of Nigeria

Dr. John G. Breslin Lecturer (tenured academic) at NUI Galway's College of Engineering and Informatics (Electronic Engineering) [2008-present]

-Teaching fundamental topics to all engineering and computer science students -Advanced courses to electrical, computer, energy, sports and exercise students - Over 140 peer-reviewed publications

- Chair of various international conferences (AAAI ICWSM-12, BlogTalk '08-'10) - Research leader of the Unit for Social Software at Insight (formerly DERI) [2006-present] -Team lead at NUI Galway's world-leading web research institute -Directing a team of 12 researchers

-Researching the application of Social Semantic Web to journalism, health and fitness, government, energy

- Creator of the SIOC project, results of which have been implemented in hundreds of applications on tens of thousands of websites

-Co-author of the book "Social Semantic Web"

-Leader of the Eurapp app economy study

-Vice Chair of the International Federation for Information Processing Working

-Group 12.7 on Social Networking Semantics and Collective Intelligence

-Dissemination Chair for the KEYSTONE European COST Action IC1302

Internet entrepreneur

-Co-founder and director, boards i.e., Ltd. (Ireland's largest forum community, over 2.25 M visitors per month) [2000]

-Co-founder, Adverts Marketplace Ltd. (adverts i.e., online classified adverts service) [2006]

-Co-founder, StreamGlider Inc. (real-time streaming newsreader for tablets) [2011]

-Founder, Technology Voice (online publisher) [2012]

-Member of the Board of Directors, American Council on Exercise [2013-]

-Advisor, CrowdGather Inc., Dot-Irish LLC, Trugence Inc., BuilderEngine, CloudDock, Pocket Anatomy, Fimsi 